\title{
First molecular characterization of Sarcocystis neurona causing meningoencephalitis in a domestic cat in Brazil
}

\author{
Márcia Elisa Hammerschmitt ${ }^{1}$ (D) - Luan Cleber Henker ${ }^{1}$. Juliana Lichtler ${ }^{2}$. Fernanda Vieira Amorim da Costa ${ }^{2}$. \\ Rodrigo Martins Soares ${ }^{3} \cdot$ Horwald Alexander Bedoya Llano $^{3} \cdot$ Saulo Petinatti Pavarini $^{1}$
}

Received: 19 September 2019 / Accepted: 4 December 2019 / Published online: 4 January 2020

(C) Springer-Verlag GmbH Germany, part of Springer Nature 2020

\begin{abstract}
Sarcocystis neurona is the main agent associated with equine protozoal myeloencephalitis (EPM). Apart from horses, $S$. neurona has been occasionally described causing neurologic disease in several other terrestrial animals as well as mortality in marine mammals. Herein, we describe the clinical, pathological, and molecular findings of a fatal case of $S$. neurona-associated meningoencephalitis in a domestic cat. The causing agent was analyzed by multilocus genotyping, confirming the presence of $S$. neurona DNA in the tissue samples of the affected animal. Significant molecular differences were found in relation to $S$. neurona isolates detected in other regions of the Americas. In addition, the parasite was identical to Sarcocystis sp. identified in opossum sporocysts in Brazil at molecular level, which suggests that transmission of. S. neurona in Brazil might involve variants of the parasite different from those found elsewhere in the Americas. Studies including more samples of S. neurona would be required to test this hypothesis, as well as to assess the impact of this diversity.
\end{abstract}

Keywords Protozoal meningoencephalitis $\cdot$ Feline $\cdot$ Genotyping $\cdot$ Polymerase chain reaction

Section Editor: Daniel K. Howe

Electronic supplementary material The online version of this article (https://doi.org/10.1007/s00436-019-06570-w) contains supplementary material, which is available to authorized users.

Márcia Elisa Hammerschmitt marciahammer@hotmail.com

1 Setor de Patologia Veterinária, Departamento de Patologia Clínica, Faculdade de Veterinária, Universidade Federal do Rio Grande do Sul, Av. Bento Gonçalves, 9090, Bairro Agronomia, Porto Alegre, RS 91540-000, Brazil

2 Setor de Medicina Felina, Hospital de Clínicas Veterinárias, Faculdade de Veterinária, Universidade Federal do Rio Grande do Sul, Av. Bento Gonçalves, 9090, Bairro Agronomia, Porto Alegre, RS 91540-000, Brazil

3 Departamento de Medicina Veterinária Preventiva e Saúde Animal, Faculdade de Medicina Veterinária e Zootecnia, Universidade de São Paulo, Av. Prof. Dr. Orlando Marques de Paiva, 87, Cidade Universitária, São Paulo, SP 05508-270, Brazil

\section{Introduction}

Sarcocystis neurona, Sarcocystis speeri, and Sarcocystis falcatula are very similar species, transmitted exclusively in the Americas by opossums of the genus Didelphis spp. (Dubey et al. 2015). S. neurona and S. falcatula have already been described in Brazil. Birds of various species are susceptible to $S$. falcatula, while mammals, predominantly, are susceptible to $S$. neurona/S. speeri (Dubey et al. 2015). It is worth mentioning that $S$. neurona and $S$. speeri are almost identical species according to criteria based on molecular identification (Cesar et al. 2018; Acosta et al. 2018).

Sarcocystis neurona is the main agent associated with equine protozoal myeloencephalitis (EPM), an important neurologic disease of horses in the American continent (Dubey et al. 2015). In addition, neurologic disease caused by $S$. neurona has been occasionally described in several other terrestrial animals (Dubey et al., 2000), and this parasite has arisen as a significant cause of mortality in marine mammals (Barbosa et al. 2015). Opossums, Didelphis virginiana in North America (Fenger et al. 1995) and Didelphis albiventris in South America (Dubey et al., 2001a), are known definitive 
hosts of $S$. neurona, while intermediate hosts include domestic cats, sea otters, armadillos, raccoons, and skunks (Dubey et al., 2001b). Central nervous system (CNS) disease caused by $S$. neurona has been rarely described in domestic cats (Dubey et al., 1994, 2003).

Therefore, the objective of this study is to describe the clinical, pathological, immunohistochemical, and molecular findings of a fatal case of $S$. neurona-associated meningoencephalitis in a domestic cat in Southern Brazil.

\section{Material and methods}

\section{Animal}

A 1.7-year-old domestic cat, with free access to the street, presented a clinical history of anorexia and dyspnea, which lasted 7 days. At clinical examination, hyperthermia and pleural effusion were detected. Serological tests yielded positive results for feline leukemia virus (FeLV) and negative results for feline immunodeficiency virus (FIV). Pleural effusion was submitted for cytological evaluation, and pyogranulomatous inflammation was observed. Thoracic effusion was subjected for coronavirus immunocytochemistry, yielding negative results. Thoracic radiography was performed, and a radiopaque area in the cranial mediastinal region was noted. Due to the clinical suspicion of mediastinal lymphoma, chemotherapeutic treatment was prescribed. Treatment with prednisolone (2 mg/kg, S.I.D., P.O.) was established, associated with vincristine administrations with a 7-day interval $(0.75 \mathrm{mg} / \mathrm{m} 2$, I.V.). In addition, a single administration of cyclophosphamide $(250 \mathrm{mg} / \mathrm{kg}$, P.O.), at the third week after treatment onset, was prescribed. Twenty-one days after the first clinical examination, the cat returned to the hospital presenting neurological signs, such as compulsive walking, head pressing, and vocalization. The cat died and was referred for necropsy. At the necropsy, the animal showed severe dehydration, emaciation, as well as mild cerebellar herniation through the foramen magnum. No mass consistent with lymphoma was evidenced at the mediastinal region or any other organ. In addition, no cavitary effusions or inflammatory lesions compatible com FIP were observed. At necropsy, multiple tissue samples were collected and fixed in a $10 \%$ neutral buffered formalin solution. Samples were routinely processed for histopathological examination and stained with hematoxylin and eosin (HE). Fresh frozen samples of brain and cerebellum were collected and posteriorly submitted for DNA extraction and molecular analysis. At the histological examination, lesions were restricted to the encephalon (spinal cord was not available for evaluation). In the gray and white matter and sometimes extending to the leptomeninges (Fig. 1a), there was a marked inflammatory infiltrate consisting of degenerate neutrophils, macrophages, and lymphocytes (Fig. 1b). These areas were often associated with parasitic structures measuring $10-15 \mu \mathrm{m}$ in diameter (schizonts), which contained numerous elongated structures measuring around $1.5 \times 4 \mu \mathrm{m}$ (merozoites), morphologically consistent with $S$. neurona (Fig. 1c). Schizonts were observed freely in the midst of inflammation areas, as well as in the soma of neurons and in the cytoplasm of astrocytes. In addition, multifocal moderate to severe perivascular inflammatory infiltrate of lymphocytes, plasma cells, and macrophages was seen in the brain and in the cerebellum. Furthermore, multifocal areas of gliosis associated with gemistocytic astrocytes, few gitter cells, and endothelial cell hypertrophy were seen. Lesions were marked in the telencephalon, diencephalon, cerebellum, and corpus striatum, and moderate in the mesencephalon and in the brainstem.

\section{Immunohistochemistry}

CNS sections were submitted for immunohistochemistry antiS. neurona (polyclonal antibody non-commercial, 1:200), anti-Toxoplasma gondii (VRMD, Pullman, WA, USA, dilution of 1:1000), and anti-Neospora caninum (VRMD, Pullman, WA, USA, dilution of 1:1000). Antigen retrieval was performed with proteinase $\mathrm{K}$ for $1 \mathrm{~min}$ for $S$. neurona and $0.1 \%$ trypsin for $10 \mathrm{~min}$ for $N$. caninum and T. gondii. Blocking of nonspecific reactions was performed with $5 \%$ skim milk for $15 \mathrm{~min}$. The amplification signal was achieved by using MACH 4 Universal HRP-Polymer (Biocare, Pacheco, CA, USA) for S. neurona and LSAB-HRP Universal kit (Dakocytomation, Carpinteria, CA, USA) for N. caninum and T. gondii. The reactions were visualized with 3-amino-9ethylcarbazole chromogen (AEC; Sigma, St. Louis, Missouri, USA), and subsequently, all slides were counterstained with Harris' hematoxylin. Positive control samples consisted of known cases of CNS disease caused by $S$. neurona, T. gondii, and N. caninum. In the negative control slides, primary antibodies were replaced by PBS.

\section{DNA extraction, PCR amplification, and sequencing}

DNA was extracted from frozen samples of the brain of the infected cat with DNeasy Blood \& Tissue Kit (Qiagen, Hilden, Germany) as recommended by the manufacturer's, except for elution of the final product in $50 \mu \mathrm{L}$ of AE buffer. The DNA samples were tested for the presence of $S$. neurona by means of multilocus genotyping as described below.

Sarcocystis spp. sequences of $18 \mathrm{~S}$ small subunit rRNA region, gene coding for cytochrome c oxidase subunit I, and internal transcribed spacer $1, \mathrm{SAG} 2, \mathrm{SAG} 3$, and SAG4 were nested PCR amplified. Nested PCR directed to 18S (nPCR$18 \mathrm{~S}$ ) was performed using primers $18 \mathrm{~S} 9 \mathrm{~L}$ and $18 \mathrm{~S} 1 \mathrm{H}$ (Li et al. 2002). DNA amplification of Sarcocystis spp. cytochrome c oxidase subunit I (nPCR-COX1) was performed using primers designed by Gondim et al. (2019). Complete internal 


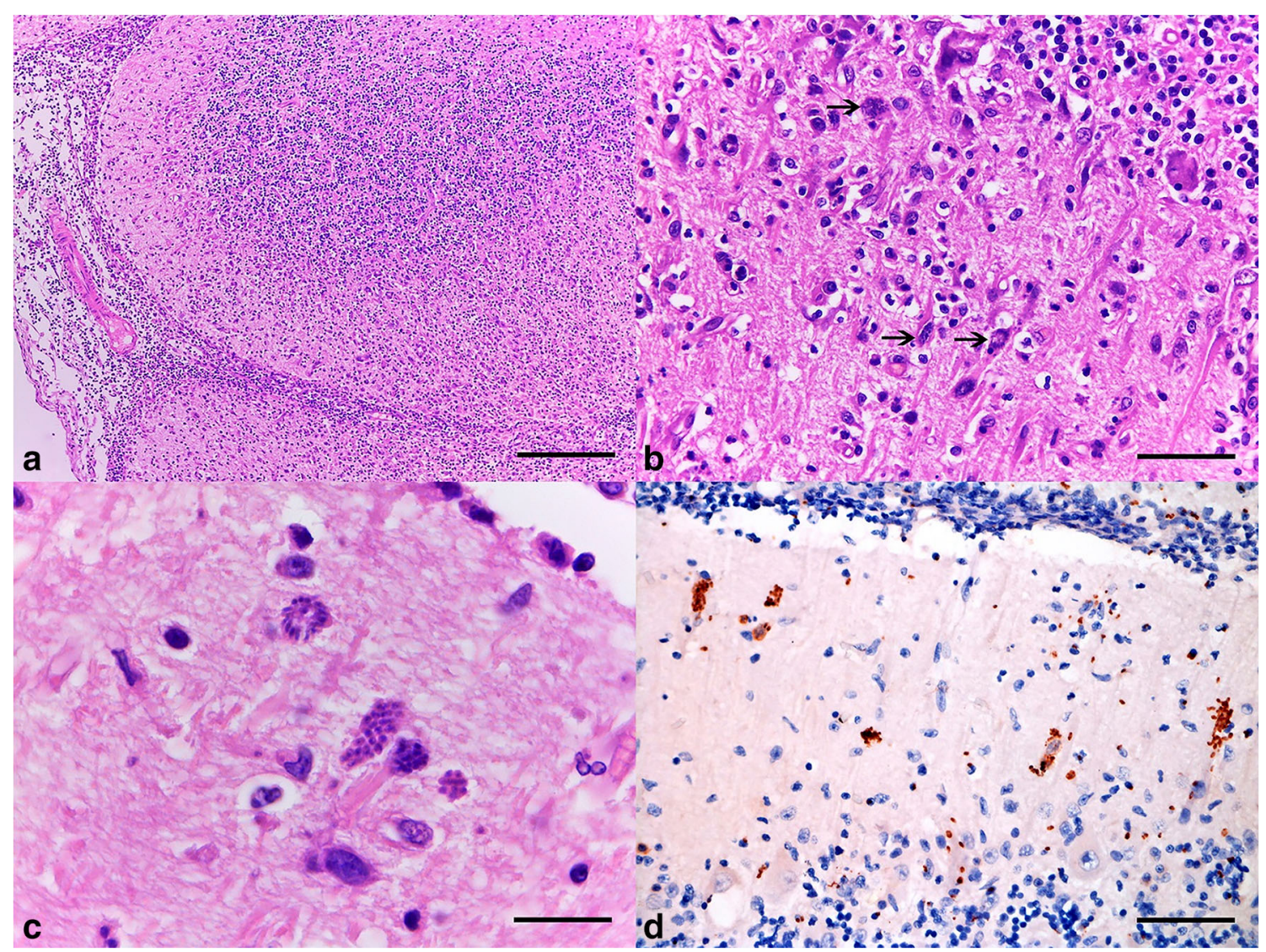

Fig. 1 S. neurona-associated meningoencephalitis in a domestic cat. a Cerebellum, marked diffuse mixed inflammatory infiltrate is observed distending the leptomeninges as well as partially effacing the neuropile or the trilaminar aspect of the cerebellum. HE, bar $300 \mu \mathrm{m}$. b Cerebellum, there is moderate inflammatory infiltrate of lymphocytes, plasmocytes and macrophages associated with parasitic schizonts (arrows). HE, bar

transcribed spacer 1 was nested PCR amplified using the primer set described by Soares et al. (2011). Finally, genetic sequences of SAG2, SAG3, and SAG4 were nested PCR amplified using the primers as designed in Monteiro et al. (2013), Valadas et al. (2016), and Gondim et al. (2019). Primers used to amplify genetic sequences of Sarcocystis spp. using nested PCR are depicted in Table 1.

DNA amplification was done in two rounds, in all cases. The first round of amplifications (external primers) was conducted by adding $4 \mu \mathrm{L}$ of extracted DNA, $2.5 \mu \mathrm{L}$ of $10 \mathrm{x}$ PCR Buffer (KCL $50 \mathrm{mM}$; Tris $\mathrm{HCl} 10 \mathrm{mM}$; pH 9.0), $1 \mu \mathrm{L}$ of MgCL2 $(50 \mathrm{mM}), 0.5 \mu \mathrm{L}$ of mixed dNTPs $(10 \mathrm{mM})$, $0.35 \mu \mathrm{L}$ of each primer $(10 \mu \mathrm{M}), 0.2 \mu \mathrm{L}$ of Taq DNA Polymerase Platinum-Invitrogen $(5 \mathrm{U} / \mu \mathrm{L})$, and $16.1 \mu \mathrm{L}$ of ultrapure autoclaved water to a volume of $25 \mu \mathrm{L}$ per reaction. The PCR thermal cycling consisted of an initial incubation at $94{ }^{\circ} \mathrm{C}$ for $3 \mathrm{~min}$, followed by 40 cycles $\left(94{ }^{\circ} \mathrm{C}\right.$ for $30 \mathrm{~s}, 56^{\circ} \mathrm{C}$ for $30 \mathrm{~s}, 72{ }^{\circ} \mathrm{C}$ for $50 \mathrm{~s}$ ) and a final extension at $72{ }^{\circ} \mathrm{C}$ for $5 \mathrm{~min}$. For the second rounds of amplifications (internal primers), $2 \mu \mathrm{L}$ of template derived from the first reactions was added to $2.5 \mu \mathrm{L}$ of $10 \mathrm{x}$ PCR Buffer (KCL $50 \mathrm{mM}$; Tris
$100 \mu \mathrm{m}$. c Cerebellum, multiple schizonts of $S$. neurona filled by numerous elongated structures (merozoites) are seen in the neuropile. HE, bar $30 \mu \mathrm{m}$. d Cerebellum, marked multifocal anti-S. neurona immunostaing is noted in the neuropile. Numerous schizonts and merozoites are evidenced freely in the neuropile, as well as in the cytoplasm of CNS cells. IHC, chromogen AEC, bar $45 \mu \mathrm{m}$

HCl $10 \mathrm{mM}$; pH 9.0), $1 \mu \mathrm{L}$ of MgCL2 (50 mM), $0.5 \mu \mathrm{L}$ of mixed dNTPs $(1.25 \mathrm{mM}), 1 \mu \mathrm{L}$ of each primer $(10 \mu \mathrm{M})$, $0.2 \mu \mathrm{L}$ of Taq DNA Polymerase Platinum-Invitrogen (5 U/ $\mu \mathrm{I})$, and $16.8 \mu \mathrm{L}$ of ultrapure autoclaved water to a volume of $25 \mu \mathrm{L}$ per reaction. The thermal cycling was the same used in the first round.

The nested PCR products were analyzed under ultraviolet transilluminator after electrophoresis in $2 \%$ agarose gels and ethidium bromide $(0.5 \mu \mathrm{g} / \mathrm{mL})$ staining for $60 \mathrm{~min}$. The targeted bands were excised from the gel and purified using a commercial purification kit (Illustra GFX PCR DNA and Gel Band Purification, Amersham Biosciencies) according to the manufacturer's instructions. The purified DNA was bidirectionally sequenced using forward and reverse primers with the Kit ABI PRISM Big Dye Terminator (Applied Biosystem) following the manufacturer's protocol.

\section{Sequence edition and sequence analysis}

The quality of nucleotide sequences, the contig assembly, and sequence edition were assessed using the program Phred-Phrad 
Table 1 Primers for the detection of Sarcocystis spp. genetic sequences in brain tissue sample of an infected cat

\begin{tabular}{|c|c|c|c|c|c|}
\hline Locus & Primers & Sequences & PCR step ${ }^{a}$ & Size $(b p)^{b}$ & Reference \\
\hline \multirow[t]{2}{*}{$18 \mathrm{~S}$} & $18 \mathrm{~S} 9 \mathrm{~L}$ & GGATAACCTGGTAATTCTATG & $1+2$ & 825 & Li et al. 2002 \\
\hline & $18 \mathrm{~S} 1 \mathrm{H}$ & GGCAAATGCTTTCGCAGTAG & $1+2$ & & Li et al. 2002 \\
\hline \multirow[t]{4}{*}{ COX1 } & COX1-227F25 & GTTTTGGTAACTACTTTGTACCGAT & 1 & & Gondim et al. 2019 \\
\hline & COX1-885R25 & GAAATATGCACGAGTATCTACCTCT & 1 & & Gondim et al. 2019 \\
\hline & COX1-275F22 & TGTACCCACGAATTAATGCAGT & 2 & 590 & Gondim et al. 2019 \\
\hline & COX1-844R21 & GTGTGCCCATACTAGAGAACC & 2 & & Gondim et al. 2019 \\
\hline \multirow[t]{4}{*}{ ITS1 } & JS4 & CGAAATGGGAAGTTTGAAC & 1 & & Slapeta et al. 2002 \\
\hline & $\mathrm{CT} 2 \mathrm{c}$ & CTGCAATTCACATTCGC & 1 & & Soares et al. 2011 \\
\hline & JS4b & AGTCGTAACAAGGTTTCCGTAGG & 2 & $\sim 1100$ & Soares et al. 2011 \\
\hline & $\mathrm{CT} 2 \mathrm{~b}$ & TTGCGCGAGCCAAGACATC & 2 & & Soares et al. 2011 \\
\hline \multirow[t]{4}{*}{ SAG2 } & SAG2-F1 & CAACAATTGCGTGCACACAA & 1 & & Valadas et al. 2016 \\
\hline & SAG2-R1 & ACAACACTGTGAGAGATGCGA & 1 & & Monteiro et al. 2013 \\
\hline & SAG2-F2 & GGTCAGAGCTTTGTGCTGAA & 2 & 338 & Monteiro et al. 2013 \\
\hline & SAG2-459R21 & CACATTGCAAGCASGACACCA & 2 & & Gondim et al. 2019 \\
\hline \multirow[t]{3}{*}{ SAG3 } & SAG3-F1 & CTCGCAGTTGCCTGCCTTG & 1 & 511 & Monteiro et al. 2013 \\
\hline & SAG3-053F19 & GATCCACCTGTYGCAACTT & 2 & & This study \\
\hline & SAG3-589R21 & TGGTCCTGTAGCAGTAACACA & $1+2$ & & Valadas et al. 2016 \\
\hline \multirow[t]{4}{*}{ SAG4 } & SAG4-F2 & CCGAGGTACAGTTCAAGGCG & 1 & & Monteiro et al. 2013 \\
\hline & SAG4-R1 & CGACGACGATACCCAATGCC & 1 & & Monteiro et al. 2013 \\
\hline & SAG4-541F21 & GGCAACGCCGCAGCMCTGCAA & 2 & 282 & Valadas et al. 2016 \\
\hline & SAG4-803R20 & CAATGCCGAMGCGGTACGAG & 2 & & Gondim et al. 2019 \\
\hline
\end{tabular}

${ }^{a}$ (1) Primers used only in the first round of amplification, (2) primers used only in the second round of amplification, and $(1+2)$ primers used in the first and second round of amplification

${ }^{\mathrm{b}}$ Predicted size of the nested PCR product

in Codon Code Aligner, version 4.2.1. The final nucleotide sequences from each locus were analyzed using Blast search tool (https://blast.ncbi.nlm.nih.gov/Blast.cgi). ITS1 and SAG sequences were aligned with homologous sequences available in GenBank using the program Clustal W in BioEdit Sequence Alignment Editor v. 7.0.5.3 (Hall 1999). ITS1 phylogenetic tree was inferred with maximum likelihood method, computing evolutionary distance using K2P + G method. The ITS1 phylogeny was inferred with sequences of $S$. neurona, S. speeri, $S$. falcatula, and related organisms retrieved from GenBank after Blast search tool using S. neurona from a cat as query. ITS1 phylogeny was reconstructed using sequences with more than 90\% coverage containing at most one degenerate site by using MEGA 7 (Kumar et al. 2016). The software PopART (Population Analysis with Reticulate Trees) (Leigh and Bryant 2015) was used to infer evolutionary relationships and Integer NJ networks inference method among isolates of $S$. neurona and $S$. falcatula based on SAG loci. The genetic sequences were deposited in GenBank under the following accession numbers: SAG2 MN175964, SAG3 MN175965, SAG4 MN175966, CO1 MN175967, ITS1 MN172273, and 18S MN169125.

\section{Results}

Immunohistochemistry anti-S. neurona was strongly positive (Fig. 1d), and immunohistochemistry anti-T. gondii and anti$N$. caninum were negative. Brain tissue samples were positive by all nested PCRs and the results of the multilocus analysis revealed the presence of $S$. neurona, which was called as $S$. neurona-07-2015-RS-BR. The complete nucleotide sequence of the nPCR-18S amplicon of S. neurona-07-2015-RS-BR (783 nucleotides, primers excluded) disclosed $100 \%$ identity and $100 \%$ coverage to $S$. speeri detected in opossums from Argentina (KT207459), and $99.87 \%$ identity and $100 \%$ coverage to S. falcatula detected in fatal Sarcocystis infection in the Rainbow Lorikeets (Trichoglossus moluccanus) (isolate Lorikeet \#205850, MH626537) (Verma et al. 2018). A G-A substitution differs $S$. neurona-07-2015-RS-BR and $S$. falcatula isolate Lorikeet \#205850 at nucleotide position 30 (taking MH626537 as reference). Only two single nucleotide polymorphisms differ $S$. falcatula isolate Lorikeet \#205850 from $S$. speeri among 1618 paired nucleotides (G-A and CA substitutions at nucleotide positions 30 and 1563, respectively, taking MH626537 as reference). nPCR-COX1 
products of $S$. neurona-07-2015-RS-BR (547 nucleotides, primers excluded) differs from both $S$. falcatula (MH665257) and S. speeri (KT207461) at two nucleotide positions (A-T and C-A substitutions at nucleotide positions 347 and 497, respectively, taking KT207461 as reference). Curiously, S. falcatula MH665257 and S. speeri KT207461 disclosed $100 \%$ identity and $100 \%$ coverage among 1002 paired nucleotides. No gap was included in the alignments of $18 \mathrm{~S}$ and COX1 from S. neurona-07-2015-RS-BR, S. falcatula isolate \#205850, and S. speeri.

The almost complete nPCR-ITS1 amplicon was sequenced from S. neurona-07-2015-RS-BR (992 nucleotides). From the Blast search, the ITS1 sequence of $S$. neurona-07-2015-RSBR is most similar to $S$. speeri detected in opossums in Argentina (KT207458), showing 97.89\% identity, including 10 gaps. From the sequences annotated as S. falcatula, the most similar to $S$. neurona-07-2015-RS-BR is $S$. falcatula isolate Lorikeet \#205850 (MH626538). These sequences share $97.08 \%$ nucleotide identity, including 16 gaps. ITS1 phylogenetic tree including S. falcatula, S. neurona, S. speeri, and $S$. falcatula related sequences can be found in Fig. 2. Curiously, the topology of the ITS1 tree shows that $S$. neurona-07-2015-RS-BR is clearly divergent from $S$. neurona/S. speeri. The monophyly of $S$. neurona/S. speeri/S. neurona-07-2015-RS-BR clade is supported with low bootstrap value $(<70$, not shown).

Evolutionary relationships among $S$. neurona and $S$. falcatula inferred with SAG loci revealed that $S$. neurona07-2015-RS-BR clustered closer to S. neurona (Fig. 3). In addition to $S$. neurona, the networks in Fig. 3 included $S$. falcatula obtained from budgerigars that were experimentally infected with opossum's sporocysts (Gondim et al. 2017, Cesar et al. 2018) and S. falcatula directly detected in intermediate hosts (Konradt et al. 2017, Acosta et al. 2018). At the three SAG loci, S. neurona-07-2015-RS-BR was identical to Sarcocystis sp. genotype II derived from opossum's sporocysts in the state of Rio Grande do Sul, Brazil, described by Monteiro et al. (2013).

\section{Discussion}

In the present study, the diagnosis of $S$. neurona-associated meningoencephalitis in a domestic cat was established through the association of the pathological, immunohistochemical, and molecular findings. Data regarding CNS disease caused by $S$. neurona in domestic cats are scarce. In North America, a recent case report described encephalomyelitis in an 8-year-old cat associated with $S$. neurona-like infection. The ITS1 sequence showed the most similarity with $S$. neurona and S. dasypi (Zitzer et al. 2017). The experimental infection of domestic cats by $S$. neurona, with subsequent formation of cysts in their muscular tissue, has been reported
(Dubey et al., 2001b), which suggests that cats may act as one of the intermediate hosts of $S$. neurona, at least in experimental conditions. Studies conducted in Michigan (Rossano et al. 2002), Missouri (Turay et al. 2002), and Ohio (Stanek et al. 2003) revealed antibodies to $S$. neurona in feral cats, indicating possible exposure and natural infection by $S$. neurona in domestic felines with access to the outdoors in general, similarly to what was observed in the present case. However, in some of the mentioned studies, antibody cross-reactivity against other closely Sarcocystis species could not be completely rule out (Rossano et al. 2002).

Rapid reproduction after oral infection of the intermediate hosts is likely responsible for the clinical manifestations (Wünschmann et al. 2009). Possibly, the use of corticosteroids, FeLV infection, and chemotherapy had great importance in the development of the clinical condition in the present case. Similarly, other immunosuppressive factors such as lesions, surgery, and stressful events have been associated with S. neurona infection in horses (Saville et al. 2001, Cooley et al. 2007). It has been suggested that the use of corticosteroids influences the proliferation of the protozoan in the CNS (Cooley et al. 2007), which may explain the aggravation of the clinical condition.

Microscopic lesions observed in the inspected organs were restricted to the brain and cerebellum and were characterized by meningoencephalitis associated with intralesional parasitic structures compatible with $S$. neurona, confirmed by immunohistochemistry and PCR. Inflammatory lesions were marked in the present case; however, unlike horses, in which S. neurona is rarely observed (Dubey et al. 2015), numerous parasites were noted within areas of inflammation. Toxoplasma gondii and N. caninum, two coccidians candidates that could be also involved in neurological infections, were ruled out because nPCR-ITS1 are capable of detecting both sarocystinae and toxoplasmatinae and genetic sequences of the latter was not found. In addition, immunohistochemistry anti- $N$. caninum and anti- $T$. gondii were negative.

To our knowledge, this is the first report on molecular characterization of $S$. neurona detected in a case of neurologic disease affecting an animal in Brazil. Sarcocystis neurona and S. falcatula are closely related organisms exclusively transmitted within the American continents that use opossums of the genus Didelphis as definitive hosts. Despite morphological and molecular similarities, $S$. neurona infects mammals predominantly, while $S$. falcatula exclusively infects birds. Two evolutionarily distant strains have been well recognized among isolates of $S$. falcatula in the Americas (Valadas et al. 2016, Gondim et al. 2017, Cesar et al. 2018), and to our knowledge, a similar situation has not yet been detected in $S$. neurona, which appeared to be formed by only one genetic lineage. However, from the results presented here, it is probable that this diversity also occurs within $S$. neurona. The characterization of the ITS1 locus of the $S$. neurona-07- 


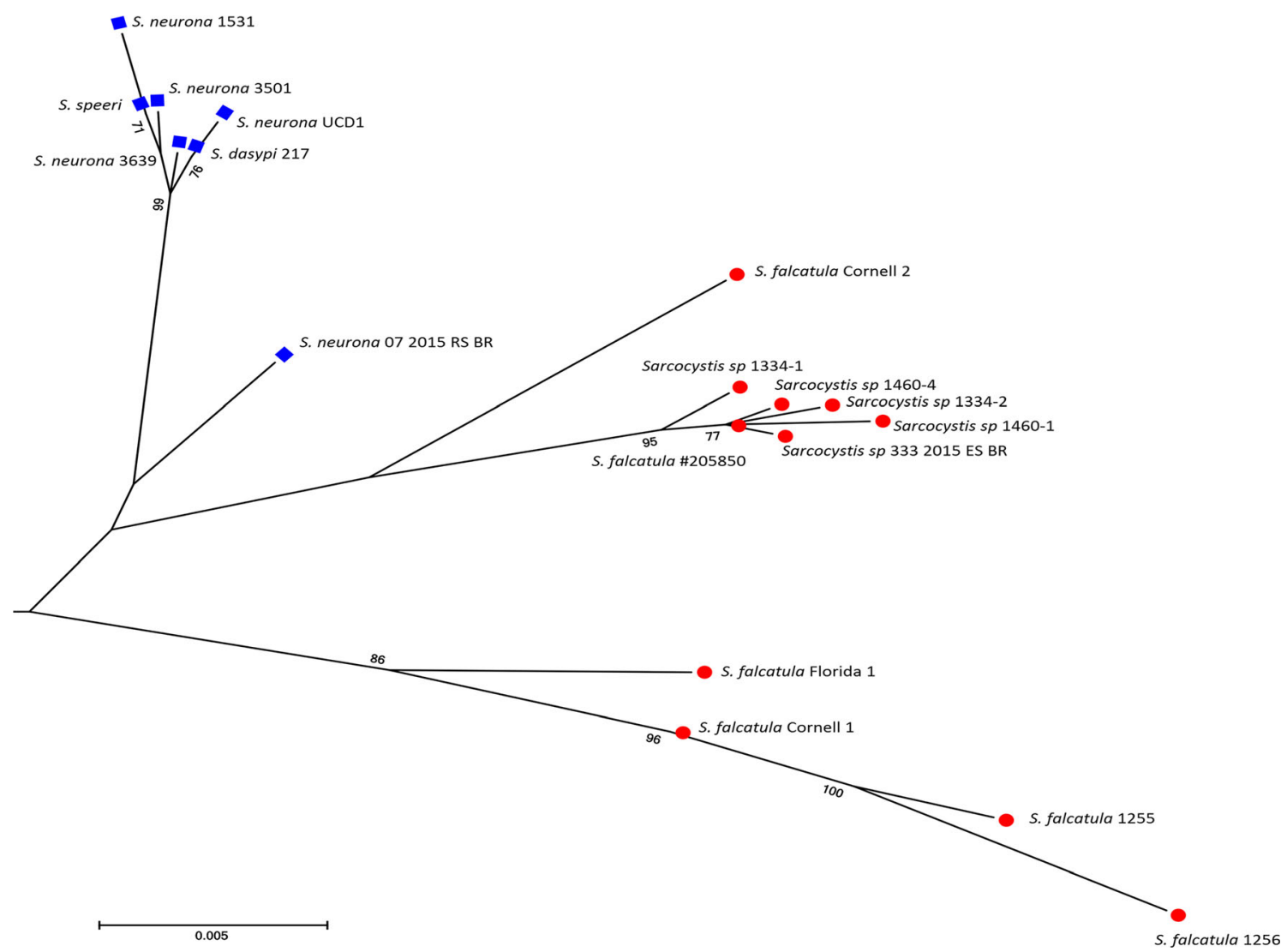

Fig. 2 Evolutionary relationships among S. neurona, S. speeri, and S. falcatula inferred with ITS1. The tree is rooted with S. lindsayi. Bootstraps values less than 70 are not shown. S. neurona/S. speeri in blue, S. falcatula in red. The list of taxa presented in the tree is depicted in the supplementary table

2015-RS-BR isolate revealed an ITS1 lineage, which is considerably distant from other organisms classified as $S$. neurona (including $S$. speeri). By ITS1-based analysis, $S$. speeri, found in sporocysts of opossums in Argentina, is almost identical to
S. neurona isolates found in several other hosts in North America and the clade that congregates all species of $S$. neurona and $S$. speeri with high statistical support excludes S. neurona-07-2015-RS-BR isolate.
Fig. 3 Phylogenetic networks on SAG2, SAG3, and SAG4 genotypes from Sarcocystis spp. Sarcocystis neurona-07-2015RS-BR is represented by genotype \#II in all networks. $S$. neurona in blue, $S$. falcatula in red. The size of the circles is proportional to the number of samples. Mutations are shown in hatch marks. The list of taxa presented in the networks is depicted in the supplementary table

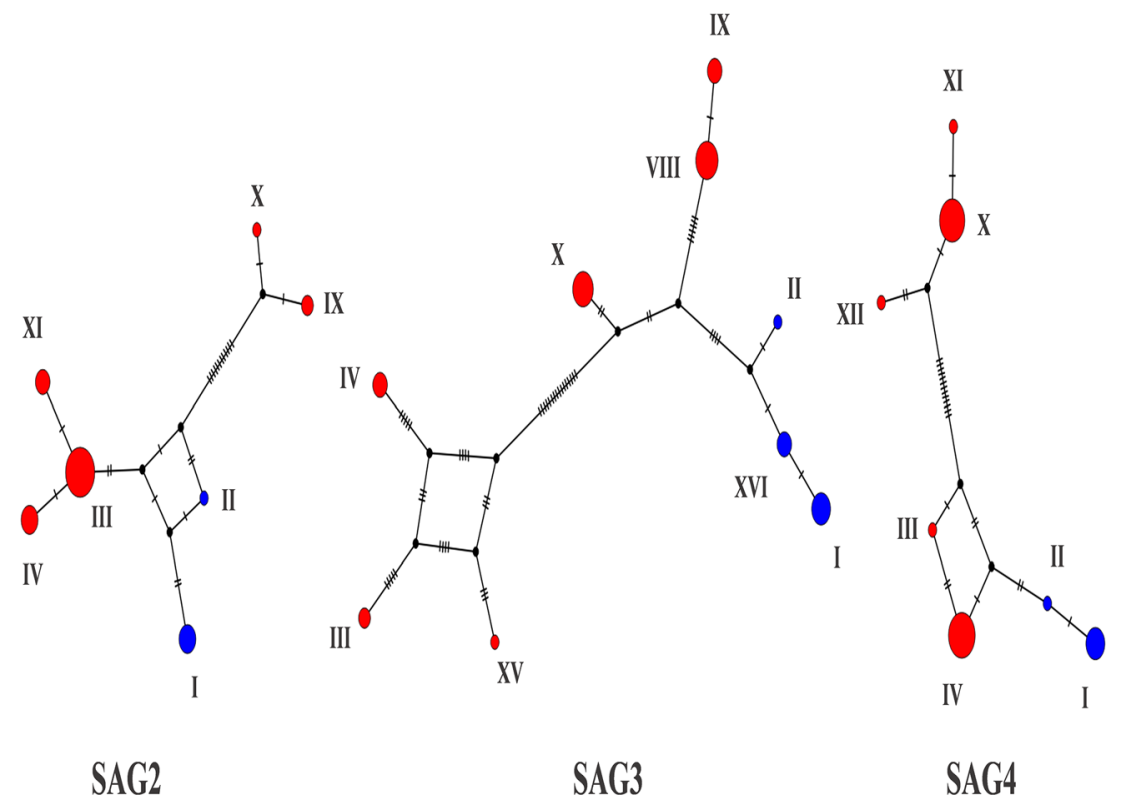


Although COX1-based analysis does not distinguish $S$. speeri and $S$. falcatula, both species differ from the $S$. neurona-07-2015-RS-BR isolate by two nucleotide substitutions. It is worth noting that two nucleotide substitutions (considering the segment homologous to nPCR-COX1 fragment) differentiate S. halieti (MH138308) from S. turdusi (KT588511), S. lari (MF596283), and S. lutrae (MG273670), which are all recognized as distinct species (data not shown).

Herein, the divergence of isolate S. neurona-07-2015-RSBR from $S$. neurona was further investigated with the SAG loci and the isolate 07-2015-RS-BR reveals, although not identical, very closely related to other samples of $S$. neurona, which allows concluding that the sarcocystid isolate found in the cat investigated may in fact be classified as S. neurona.

From the analysis of SAG2, SAG3, and SAG4, S. neurona07-2015-RS-BR was identical to Sarcocystis sp. identified in opossum sporocysts in the state of Rio Grande do Sul, Brazil (Monteiro et al. 2013), indicating that variants of S. neurona different from those occurring elsewhere in the Americas are being transmitted in Brazil. Studies including more samples of S. neurona would be required to test this hypothesis, as well as to assess the impact of this diversity.

Acknowledgments We thank Dr. Marcele Bettim Bandinelli by performing immunohistochemistry. The authors thank Conselho Nacional de Desenvolvimento Científico e Tecnológico (CNPQ) and Coordenação de Aperfeiçoamento de Pessoal de Nível Superior (CAPES) for the financial support.

\section{Compliance with ethical standards}

Conflict of interest The authors declare that they have no conflict of interest.

\section{References}

Acosta ICL, Soares RM, Mayorga LFSP et al (2018) Occurrence of tissue cyst forming coccidia in Magellanic penguins (Spheniscus magellanicus) rescued on the coast of Brazil. PLoS One. https:// doi.org/10.1371/journal.pone.0209007

Barbosa L, Johnson CK, Lambourn DM et al (2015) A novel Sarcocystis neurona genotype XIII is associated with severe encephalitis in an unexpectedly broad range of marine mammals from the northeastern Pacific Ocean. Int J Parasitol 100:117-129. https://doi.org/10.1016/ j.ijpara.2015.02.013

Cesar MO, Matushima ER, Zwarg T, de Oliveira AS, Sanches TC, Joppert AM, Keid LB, Oliveira TMFS, Ferreira HL, Llano HAB, Konradt G, Bianchi MV, Gregori F, Gondim LFP, Soares RM (2018) Multilocus characterization of Sarcocystis falcatula-related organisms isolated in Brazil supports genetic admixture of high diverse SAG alleles among the isolates. Exp Parasitol 188:42-49. https:// doi.org/10.1016/j.exppara.2018.03.004
Cooley AJ, Barr B, Rejmanek D (2007) Sarcocystis neurona encephalitis in a dog. Vet Pathol 44(6):956-961. https://doi.org/10.1354/vp.446-956

Dubey JP, Benson J, Larson MA (2003) Clinical Sarcocystis neurona encephalomyelitis in a domestic cat following routine surgery. Vet Parasitol 112:261-267. https://doi.org/10.1016/S0304-4017(03) 00019-0

Dubey JP, Higgins RJ, Barr BC, Spangler WL, Kollin B, Jorgensen LS (1994) Sarcocystis- associated meningoencephalomyelitis in a cat. J Vet Diagn Investig 6:118-120

Dubey JP, Howe DK, Furr M, Saville WJ, Marsh AE, Reed SM, Grigg ME (2015) An update on Sarcocystis neurona infections in animals and equine protozoal myeloencephalitis (EPM). Vet Parasitol 209: 1-42. https://doi.org/10.1016/j.vetpar.2015.01.026

Dubey JP, Lindsay DS, Kerber CE, Kasai N, Pena HF, Gennari SM, Kwok OC, Shen SK, Rosenthal BM (2001b) First isolation of Sarcocystis neurona from the South American opossum, Didelphis albiventris, from Brazil. Vet Parasitol 95:295-304. https://doi.org/ 10.1016/S0304-4017(00)00395-2

Dubey JP, Lindsay DS, Saville WJA, Reed SM, Granstrom DE, Speer CA (2001a) A review of Sarcocystis neurona and equine protozoal myeloencephalitis (EPM). Vet Parasitol 95:89-131. https://doi.org/ 10.1016/S0304-4017(00)00384-8

Dubey JP, Saville WJA, Lindsay DS et al (2000) Completion of the life cycle of Sarcocystis neurona. J Parasitol 86:1276-1280. https://doi. org/10.1645/0022-3395(2000)086[1276:COTLCO]2.0.CO;2

Fenger CK, Granstrom DE, Langemeier JL, Stamper S, Donahue JM, Patterson JS, Gajadhar AA, Marteniuk JV, Xiaomin Z, Dubey JP (1995) Identification of opossums (Didelphis virginiana) as the putative definitive host of Sarcocystis neurona. J Parasitol 81:916-919. https://doi.org/10.2307/3284040

Gondim LSQ, Jesus RF, Ribeiro-Andrade M, Silva JCR, Siqueira DB, Marvulo MFV, Aléssio FM, Mauffrey JF, Julião FS, Savani ESMM, Soares RM, Gondim LFP (2017) Sarcocystis neurona and Neospora caninum in Brazilian opossums (Didelphis spp.): molecular investigation and in vitro isolation of Sarcocystis spp. Vet Parasitol 243: 192-198. https://doi.org/10.1016/j.vetpar.2017.07.002

Gondim LFP, Soares RM, Tavares AS, Borges-Silva W, de Jesus RF, Llano HAB, Gondim LQ (2019) Sarcocystis falcatula-like derived from opossum in Northeastern Brazil: in vitro propagation in avian cells, molecular characterization and bioassay in birds. Int J Parasitol Parasites Wildl 10:132-137. https://doi.org/10.1016/j.ijppaw.2019. 08.008

Hall TA (1999) BioEdit: a user-friendly biological sequence alignment editor and analysis program for Windows 95/98/NT. Nucleic Acids Symp Ser 41:95-984

Konradt G, Bianchi MV, Leite-Filho RV, da Silva BZ, Soares RM, Pavarini SP, Driemeier D (2017) Necrotizing meningoencephalitis caused by Sarcocystis falcatula in bare-faced íbis (Phimosus infuscatus). Parasitol Res 116:809-812. https://doi.org/10.1007/ s00436-016-5341-6

Kumar S, Stecher G, Tamura K (2016) MEGA7: molecular evolutionary genetics analysis version 7.0 for bigger datasets. Mol Biol Evol 33(7):1870-1874. https://doi.org/10.1093/molbev/msw05

Leigh JW, Bryant D (2015) PopART: full-feature software for haplotype network construction. Methods Ecol Evol 6(9):1110-1116

Li QQ, Yang ZQ, Zuo YX, Attwood SW, Chen XW, Zhang YP (2002) A PCR-based RFLP analysis of Sarcocystis cruzi (Protozoa: Sarcocystidae) in Yunnan Province, PR China, reveals the water buffalo (Bubalus bubalis) as a natural intermediate host. J Parasitol $88: 1259-1261$

Monteiro RM, Keid LB, Richtzenhain LJ et al (2013) Extensively variable surface antigens of Sarcocystis spp. infecting Brazilian marsupials in the genus Didelphis occur in myriad allelic combinations, suggesting sexual recombination has aided their diversification. Vet Parasitol 196:64-70. https://doi.org/10.1016/j.vetpar.2013.01.019 
Rossano MG, Murphy AJ, Vrable RA, Vanzo NE, Lewis SK, Sheline KD, Kaneene JB, Mansfield LS (2002) Cross-sectional study of serum antibodies against Sarcocystis neurona in cats tested for antibodies against. Toxoplasma gondii J Am Vet Med Assoc 221:511514

Saville WJA, Stich RW, Reed SM, Njoku CJ, Oglesbee MJ, Wunschmann A, Grover DL, Larew-Naugle AL, Stanek JF, Granstrom DE, Dubey JP (2001) Utilization of stress in the development of an equine model for equine protozoal myeloencephalitis. Vet Parasitol 95:211-222. https://doi.org/10.1016/S0304-4017(00) 00421-0

Slapeta JR, Koudela B, Votýpka J et al (2002) Coprodiagnosis of Hammondia heydorni in dogs by PCR based amplification of ITS 1 rRNA: differentiation from morphologically indistinguishable oocysts of Neospora caninum. Vet J 163:147-154. https://doi.org/10. $1053 /$ tvj1.2001.0599

Soares RM, Lopes EG, Keid LB, Sercundes MK, Martins J, Richtzenhain LJ (2011) Identification of Hammondia heydorni oocysts by a heminested-PCR (hnPCR-AP10) based on the H. heydorni RAPD fragment AP10. Vet Parasitol 175:168-172. https://doi.org/10.1016/ j.vetpar.2010.09.022

Stanek JF, Stich RW, Dubey JP et al (2003) Epidemiology of Sarcocystis neurona infections in domestic cats (Felis domesticus) and its association with equine protozoal myelooencephalitis (EPM) case farms and feral cats from a obile spay and neuter clinic. Vet Parasitol 117(4):139-149. https://doi.org/10.1016/j.vetpar.2003.09.002

Turay HO, Barr BC, Cadwell A et al (2002) Sarcocystis neurona reacting antibodies in Missouri feral domestic cats (Felis domesticus) and their role as an intermediate host. Vet Parasitol 88:38-43. https:// doi.org/10.1007/s004360100503

Valadas SYOB, Da Silva JIG, Lopes et al (2016) Diversity of Sarcocystis spp. shed by opossums in Brazil inferred with phylogenetic analysis of DNA coding ITS1, cytochrome B, and surface antigens. Exp Parasitol 164:71-78. https://doi.org/10.1016/j.exppara.2016.02.008

Verma SK, Trupkiewicz JG, Georoff T, Dubey JP (2018) Molecularly confirmed acute, fatal Sarcocystis falcatula infection in the rainbow lorikeets (Trichoglossus moluccanus) at the Philadelphia Zoo. J Parasitol 104:710-712. https://doi.org/10.1645/18-78

Wünschmann A, Rejmanek D, Cruz-Martinez L, Barr BC (2009) Sarcocystis falcatula-associated encephalitis in a free-ranging great horned owl (Bubo virginianus). J Vet Diagn Investig 21:283-287

Zitzer NC, Marsh AE, Burkhard MJ, Radin MJ, Wellman ML, Jugan M, Parker V (2017) Parasitemia due to Sarcocystis neurona -like infection in a clinically ill domestic cat. Vet Clin Pathol 46:526-532. https://doi.org/10.1111/vcp.12541

Publisher's note Springer Nature remains neutral with regard to jurisdictional claims in published maps and institutional affiliations. 